\title{
Palliative care needs of advanced cancer patients in the emergency department at the end of life: an observational cohort study
}

\author{
Mary-Joanne Verhoef ${ }^{1}$ (D) Ellen de Nijs ${ }^{1} \cdot$ Nanda Horeweg $^{2} \cdot$ Jaap Fogteloo $^{3} \cdot$ Christian Heringhaus $^{4}$. \\ Anouk Jochems ${ }^{5,6}$ - Marta Fiocco ${ }^{7,8}$. Yvette van der Linden ${ }^{1,2}$
}

Received: 15 April 2019 / Accepted: 31 May 2019 / Published online: 13 June 2019

(C) The Author(s) 2019

\begin{abstract}
Purpose Patients with advanced cancer commonly visit the emergency department (ED) during the last 3 months of life. Identification of these patients and their palliative care needs help initiating appropriate care according to patients' wishes. Our objective was to provide insight into ED visits of advanced cancer patients at the end of life.

Methods Adult palliative patients with solid tumours who died $<3$ months after their ED visit were included (2011-2014). Patients, ED visits, and follow-up were described. Factors associated with approaching death were assessed using Cox proportional hazards models.

Results Four hundred twenty patients were included, $54.5 \%$ was male, median age 63 years. A total of $54.6 \%$ was on systemic anti-cancer treatments and $10.5 \%$ received home care $\geq 1$ per day. ED visits were initiated by patients and family in $34.0 \%$ and $51.9 \%$ occurred during out-of-office hours. Dyspnoea $(21.0 \%)$ or pain $(18.6 \%)$ were most reported symptoms. Before the ED visit, limitations on life-sustaining treatments were discussed in 33.8\%, during or after the ED visit in $70.7 \%$. Median stay at the ED was 3:29 h (range 00:12-18:01 h), and 319 (76.0\%) were hospitalized. Median survival was 18 days (IQ range 7-41). One hundred four (24.8\%) died within 7 days after the ED visit, of which $71.2 \%$ in-hospital. Factors associated with approaching death were lung cancer, neurologic deterioration, dyspnoea, hypercalcemia, and jaundice.
\end{abstract}

Suggested reviewers

1. Corita R. Grudzen, NYU Emergency Medicine New York, corita.grudzen@mssm.edu

2. Barbara Gomes, Cicely Saunders Institute of Palliative Care, Policy \&

Rehabilitation, King’s College London, barbara.gomes@kcl.ac.uk

Mary-Joanne Verhoef

m.verhoef@1umc.nl

Ellen de Nijs

E.J.M.de_Nijs@1umc.nl

Nanda Horeweg

N.Horeweg@lumc.nl

Jaap Fogteloo

A.J.Fogteloo@lumc.nl

Christian Heringhaus

C.Heringhaus@lumc.nl

Anouk Jochems

a.jochems@haaglandenmc.nl

Marta Fiocco

m.fiocco@math.leidenuniv.nl

Yvette van der Linden

ymvanderlinden@lumc.nl
1 Center of Expertise Palliative Care, Leiden University Medical Center, Albinusdreef 2, 2333 ZA Leiden, the Netherlands

2 Department of Radiation Oncology, Leiden University Medical Center, Leiden, the Netherlands

3 Department of Internal Medicine, Leiden University Medical Center, Leiden, the Netherlands

4 Department of Emergency Medicine, Leiden University Medical Center, Leiden, the Netherlands

5 Department of Medical Oncology, Leiden University Medical Center, Leiden, the Netherlands

6 Department of Medical Oncology, Haaglanden Medical Center, The Hague, the Netherlands

7 Department of Biomedical Data Sciences, Leiden University Medical Center, Leiden, the Netherlands

8 Mathematical Institute, Leiden University, Leiden, the Netherlands 
Conclusion ED visits of advanced cancer patients often lead to hospitalization and in-hospital deaths. Timely recognition of patients with limited life expectancies and urgent palliative care needs, and awareness among ED staff of the potential of EDinitiated palliative care may improve the end-of-life trajectory of these patients.

Keywords Palliative care $\cdot$ Emergency department $\cdot$ Oncology $\cdot$ Terminal care

\section{Background}

Although cancer has become a chronic disease in many patients, still yearly 8.9 million patients die of widespread disease worldwide, which makes cancer a leading cause of death in developed countries [1]. To provide advanced cancer patients with a good quality at the end of life, integration of appropriate palliative care into standard care is essential [2]. Palliative care is driven by patients' care needs and wishes and must be offered while the illness is not yet life-threatening [2]. One important aspect of a good quality of end of life denoted by patients and their families is to be cared for at home and to die there $[3,4]$. Because identification of patients with limited life expectancies and urgent palliative care needs can be difficult, patients, family, and their health care professionals are often not timely prepared and educated about appropriate management of problems expected in the future given the disease trajectory. Advance care planning about patient's wishes and goals of care often take place too late. Consequently, many patients with advanced cancer and a limited life expectancy are admitted to an emergency department (ED) [5-7], leading to hospital admissions [8] and in-hospital deaths $[6,7]$. Commonly reported physical problems in patients with advanced cancer visiting the ED are pain, respiratory distress, gastro-intestinal problems, fatigue, disease progression, delirium and loss of consciousness [5, 8-11]. One study found that the most common reason for ED visits in the last 2 weeks of life was not being able to cope with the situation at home [5]. Other reasons for patients and families to go to the ED are anxiety related to the disease; being defaulted to previously used health care services; feeling safe in and familiar with the hospital setting; and difficulties accessing community health care services, especially when the complaints were urgent or occurred during out-of-office hours $[12,13]$. It is plausible that although patients consider ED visits as unwanted and as a 'last-resort' solution for relieve of their problems, their distress caused by their disease and care burden leads to these ED visits [13]. ED physicians perceive several barriers to provide appropriate palliative care: the ED is an uncomfortable setting for dying patients [14], physicians work under time pressure which makes palliative patients a low priority [15], they lack confidence in their own palliative care skills [16], do not build a long-lasting relationship with palliative patients and are consequently not comfortable with discussing limitations on medical treatments [15, 17].
Identification of advanced cancer patients with palliative care needs and a short life expectancy at the ED can help to improve the quality of the end of life by arranging appropriate care. Prediction scores for short-term death in advanced oncology patients are present, but they are not validated for the ED and are mostly extensive assessment tools requiring patient information that is not always accessible in an emergency-setting [18].

To gain more knowledge on the course of events leading to ED visits at the end of life, the objectives of this study were to provide insight into characteristics of advanced cancer patients visiting the ED, their palliative care needs, and the actions undertaken during these ED visits.

\section{Methods}

\section{Setting}

This study was conducted at the Leiden University Medical Center (LUMC) in Leiden, the Netherlands. LUMC's ED is open $24 \mathrm{~h}$ a day, 7 days a week. On average, 80 patients are evaluated every day for various reasons, including nononcological problems. Since 2011, a palliative care consultation team (PCCT) is available in the LUMC for consultation of palliative patients.

\section{Patients}

Adult patients who visited the ED between May 2011 and June 2014 were included who were in the palliative phase of cancer at the moment of the ED visit and died within 3 months thereafter. Patients were in the palliative phase if curation was not possible or if anti-cancer treatment was not directed at curation. The time period of 3 months represents the group of patients in urgent need of appropriate palliative care and appropriate end-of-life choices. Also, for the Dutch medical insurance system, this time period depicts the possibility of full reimbursement of necessary palliative home care or transfer to a hospice. Patients diagnosed with a haematological malignancy were excluded. Only data of the last ED visit before death were included. 


\section{Data collection}

Characteristics of the patients, referrals, and the ED visit and follow-up data were retrospectively collected from the electronic patients records (EPRs). The palliative disease phase was assigned by the researcher based on the disease trajectories described by Lynn and Adamson, in which three palliative phase can be discerned corresponding to the disease status: disease-modifying phase, in which anti-cancer treatment is given aimed at life prolongation or symptom management; symptom management phase, in which treatment is directed to symptom relief; or terminal phase [19]. EPRs were searched for notes reporting contact with general practitioners (GPs); for PCCT-consultations 3 months before the ED visit; and for proactive symptom management plans in files or letters until 6 weeks before the ED visit. Performance was scored using the Eastern Cooperative Oncology Group (ECOG) scale and was documented by the admitting hospital physician, or estimated by the researcher based on the patient's physical functioning documented in the EPR [20]. Limitations on lifesustaining treatments included do-not-resuscitate orders, "no ventilation'-orders and 'no intensive care unit (ICU) admission'-orders. The time of arrival at the hospital was defined as within office hours for visits from Monday to Friday between 8 a.m. and 6 p.m. The main symptom was defined as the symptom that led to the ED-referral as described in the EPR by the attending physician. New symptoms were defined as main symptoms not mentioned in the EPR 3 months before the ED visit. Acute symptoms were main symptoms with an onset within $24 \mathrm{~h}$ before the ED visit. The clinical diagnosis was defined as the conclusion of the attending ED physician.

\section{Statistics}

Characteristics of patients, referral, and ED visit were analysed using descriptive statistics. Kaplan-Meier's method was employed to estimate survival since the ED visit. The following factors associated with death were derived from literature search and clinical experience: primary lung tumour, ED-admissions for a new and acute problem, limitations on life-sustaining treatments before the ED visit, main symptom at the ED of neurologic deterioration, main symptom at the ED of dyspnoea, clinical diagnosis of bleeding, clinical diagnosis of cachexia, clinical diagnoses of hypercalcemia, and clinical diagnosis of jaundice. These factors were used in univariable and multivariable analyses by using a Cox proportional hazards regression. Predictors with a $p$ value of $<0.10$ in univariable analysis were entered in multivariable analysis. Differences with a $p$ value $<0.05$ were considered statistically significant. All analyses were conducted with SPSS 23.0 software.

\section{Results}

\section{Patient characteristics}

Four hundred twenty patients were included, median age was 63 years, and $229(54.5 \%)$ patients were male (Table 1). Tumours located in the digestive tract occurred most frequently $(27.6 \%)$. Anti-cancer treatment was provided to $73.6 \%$ of the patients in the 3 months before the ED visit. Most patients $(62.6 \%)$ were in the disease-modifying palliative phase, with average time from diagnosis of the palliative phase to ED visit of 6.2 months (range $0-13.7$ months). Most patients (92.6\%) lived at home or in a residential home before the ED visit. Home care was arranged for $21.9 \%$ of the patients, of whom $10.5 \%$ received home care at least once a day. An informal caregiver was available for $87.1 \%$ of the patients. The PCCT was consulted for 26 patients $(6.2 \%)$ in the last 3 months before the visit to the ED. Proactive symptom management plans were documented for $12.1 \%$ of the patients 6 weeks before the ED visit. Limitations on life-sustaining treatments had been discussed in $37.6 \%$ of the patients, and limitations had been documented in $33.8 \%$.

\section{Referral characteristics}

Patients or their caregivers took the initiative to visit the ED in $34.0 \%$ for a median of 2.0 symptoms (Table 2). ED visits occurred outside office hours in $51.9 \%$. The main symptom was new in $52.1 \%$ and acute in $36.9 \%$ of the patients and both new and acute in $29.3 \%$. Most frequently reported main symptoms or signs were dyspnoea (21.0\%), pain (18.6\%), and ascites $(11.9 \%)$. A total of $62.8 \%$ had an ECOG performance score of 3-4 (known in 196 of 420 patients).

\section{Visit characteristics}

At the ED, imaging and blood tests were performed in $63.3 \%$ and $83.3 \%$ of the patients, respectively (Table 3). Most frequently reported diagnoses by the attending physician were infection or fever (20.5\%), bronchopulmonary insufficiency $(12.9 \%)$, and renal insufficiency or hydronephrosis (11.2\%). Patients spent a median time at the ED equal to $3: 29 \mathrm{~h}$ (range 00:12-18:01). During or after the ED visit, limitations on life-sustaining treatments were discussed with $73.1 \%$ of the patients and $70.7 \%$ had limitations documented in the EPR. After the ED visit, $76.0 \%$ of the patients were hospitalized. Patients' median survival from the ED visit was 18 days; 104 patients (24.8\%) died within 1 week. Of the 104 patients who died within 1 week, 74 patients $(71.2 \%)$ died in the hospital and death within 1 week was associated to in-hospital death $(p<0.0001$, HR 8.49). In total, $39.3 \%$ of the patients died 
Table 1 Four hundred twenty patients with advanced oncology visiting the emergency department

\begin{tabular}{|c|c|c|}
\hline Patient characteristics & $N$ & $(\%$ of 420$)$ \\
\hline Male & 229 & $(54.5)$ \\
\hline Age in years, median (range) & 63 & $(22-92)$ \\
\hline \multicolumn{3}{|l|}{ Primary tumour site } \\
\hline Digestive tract & 116 & $(27.6)$ \\
\hline Lung & 67 & $(16.0)$ \\
\hline Gynecologic & 47 & $(11.2)$ \\
\hline Urologic & 45 & $(10.7)$ \\
\hline Breast & 37 & $(8.8)$ \\
\hline Head and neck & 32 & $(7.6)$ \\
\hline \multicolumn{3}{|l|}{ Other $^{\mathrm{a}}$} \\
\hline \multicolumn{3}{|l|}{ Time since palliative diagnosis } \\
\hline$<3$ months & 143 & $(34.0)$ \\
\hline 3 months-1 year & 144 & $(34.3)$ \\
\hline 1 year- 4 years & 98 & $(23.3)$ \\
\hline$>4$ years & 30 & $(7.1)$ \\
\hline \multicolumn{3}{|l|}{ Palliative disease phase } \\
\hline Disease-modifying & 263 & $(62.6)$ \\
\hline Symptom management & 157 & $(37.4)$ \\
\hline \multicolumn{3}{|l|}{ Treatment for primary tumour in the last 3 months } \\
\hline Chemotherapy & 168 & $(40.0)$ \\
\hline Hormonal therapy & 28 & $(6.7)$ \\
\hline Targeted or immunotherapy & 75 & $(17.9)$ \\
\hline Radiotherapy & 104 & $(24.8)$ \\
\hline Surgery & 31 & $(7.4)$ \\
\hline Other $^{\mathrm{b}}$ & 7 & $(1.7)$ \\
\hline None & 111 & $(26.4)$ \\
\hline \multicolumn{3}{|l|}{ Limitations on life-sustaining treatments } \\
\hline Not discussed & 262 & $(62.4)$ \\
\hline Discussed, no limitations documented & 16 & $(3.8)$ \\
\hline Discussed, limitations documented ${ }^{\mathrm{c}}$ & 142 & $(33.8)$ \\
\hline \multicolumn{3}{|l|}{ Current housing situation ${ }^{\mathrm{d}}$} \\
\hline At home or residential home & 389 & $(92.6)$ \\
\hline Nursing home & 12 & $(2.9)$ \\
\hline Hospice & 5 & $(1.2)$ \\
\hline \multicolumn{3}{|l|}{ Home care } \\
\hline No & 225 & $(53.6)$ \\
\hline Yes, unknown frequency & 39 & $(9.3)$ \\
\hline$<1 \times /$ day & 9 & $(2.1)$ \\
\hline$\geq 1 \mathrm{x} /$ day & 43 & $(10.5)$ \\
\hline Informal caregiver available according to EPR & 366 & $(87.1)$ \\
\hline PCCT consulted during the last 3 months & 26 & $(6.2)$ \\
\hline \multicolumn{3}{|l|}{ Proactive symptom management plans } \\
\hline In EPR, 6 weeks before the ED visit & 51 & $(12.1)$ \\
\hline In a letter to the GP, 6 weeks before the ED visit & 30 & $(7.1)$ \\
\hline Discussion with patient mentioned in EPR 6 weeks before the ED visit & 46 & $(11.0)$ \\
\hline
\end{tabular}

$P C C T$ palliative care consultation team, EPR electronic patient record, ED emergency department, GP general practitioner

${ }^{a}$ Other: other most common primary tumour sites were unknown primaries; skin tumours; sarcomas; and nasal cavity and middle ear

${ }^{\mathrm{b}}$ Other: nuclear therapy $(1 \%)$, hemo- or peritoneal dialysis $(0.2 \%)$, organ transplantation $(0.2 \%)$, and stem cell transplantation $(0.2 \%)$

${ }^{\mathrm{c}}$ Documented limitations were:?? $n$ (?\%): no resuscitation: 62 (14.8\%); no resuscitation, no ventilation: 11 (2.6\%); no resuscitation, no ventilation, no admission to the intensive care unit: 68 (16.2\%); refrain from any intervention: $1(0.2 \%)$

${ }^{\mathrm{d}}$ Current living situation was not known for 14 patients $(3.3 \%)$

at home, $29.5 \%$ in a hospital (i.e. in the clinic, intensive care unit or another hospital) and $11.0 \%$ died in a hospice. In-hospital death occurred less frequently in patients with a proactive symptom management plan sent to their GP compared to patients without $(26.9 \%$ and $38.5 \%$, respectively, $p=0.03$ ). In-hospital death was not related to limitations on life-sustaining treatments, the referrer or the number of previous admissions. 
Table 2 Referral of patients with advanced oncology to the emergency department

\begin{tabular}{|c|c|c|}
\hline Referral characteristics & $N$ & $(\%$ of 420$)$ \\
\hline \multicolumn{3}{|l|}{ Referrer } \\
\hline GP or nursing home physician & 150 & $(35.7)$ \\
\hline GP out-of-office service & 21 & $(5.0)$ \\
\hline Medical specialist & 100 & $(23.8)$ \\
\hline Patient or informal caregiver & 143 & $(34.0)$ \\
\hline Referral outside office hours & 218 & $(51.9)$ \\
\hline \multicolumn{3}{|l|}{ Referral for } \\
\hline a new problem ${ }^{\mathrm{a}}$ & 219 & $(52.1)$ \\
\hline an acute problem ${ }^{\mathrm{b}}$ & 155 & $(36.9)$ \\
\hline a new and acute problem & 123 & $(29.3)$ \\
\hline Number of symptoms, median (range) & 2.0 & $(0-7)$ \\
\hline \multicolumn{3}{|l|}{ Main symptom or sign for referral } \\
\hline Dyspnoea & 88 & $(21.0)$ \\
\hline Pain & 78 & $(18.6)$ \\
\hline Ascites & 50 & $(11.9)$ \\
\hline Nausea or vomiting & 39 & $(9.3)$ \\
\hline Fever & 38 & $(9.0)$ \\
\hline Neurologic deterioration $^{\mathrm{c}}$ & 33 & $(7.9)$ \\
\hline Bleeding & 20 & $(4.8)$ \\
\hline Weakness or loss of strength & 19 & $(4.5)$ \\
\hline Obstipation or diarrhoea & 16 & $(3.8)$ \\
\hline Difficulty swallowing or passage problems & 9 & $(2.1)$ \\
\hline Oedema & 8 & $(1.9)$ \\
\hline Seizure & 8 & $(1.9)$ \\
\hline Fatigue & 8 & $(1.9)$ \\
\hline \multicolumn{3}{|l|}{ WHO performance score } \\
\hline 0 & 4 & $(1.0)$ \\
\hline 1 & 26 & $(6.2)$ \\
\hline 2 & 43 & $(10.2)$ \\
\hline 3 & 89 & $(21.2)$ \\
\hline 4 & 34 & $(8.1)$ \\
\hline Unknown & 224 & $(53.3)$ \\
\hline
\end{tabular}

$E D$ emergency department, GP general practitioner, $W H O$ World Health Organization

${ }^{\text {a }}$ New problem: not reported in the patient records in the last 3 months

${ }^{\mathrm{b}}$ Acute problem: originated within the last $24 \mathrm{~h}$

${ }^{\mathrm{c}}$ Neurologic deterioration: confusion, drowsiness, decreased consciousness

\section{Factors associated with approaching death}

Independent risk factors for early death were primary lung tumour (HR 1.69, 95\% CI 1.29-2.21, $p<0.0001$ ), referral for neurological deterioration (HR 2.01, 95\% CI 1.38-2.92, $p<0.0001$ ) or dyspnoea (HR $1.57,95 \%$ CI $1.23-2.00$ ) and hypercalcemia (HR 1.92, 95\% CI 1.21-3.03, $p=0.005$ ) or jaundice (HR 2.11, 95\% CI 1.37-3.26, $p=0.001$ ) (Table 4).

\section{Discussion}

This study provides a detailed description of patients with advanced cancer who visited the emergency department (ED) during the last 3 months of their lives and of the actions undertaken during these ED visits. In most patients, care seemed to focus on disease modification; many patients still received anticancer treatments, and few had proactive symptom management plans in case of progressive symptoms or limitations on life-sustaining treatments documented in their patient records. The ED visit triggered revision of limitations of life-sustaining treatments in the majority of patients. Following their ED visit, $76.0 \%$ was hospitalized in poor clinical condition and $29.5 \%$ died in the hospital; of those who died within 7 days, $71.2 \%$ died in-hospital. Factors associated with approaching death were found to aid identifying those patients with urgent palliative care needs at ED entry, in order to make appropriate decisions concerning their treatment and care trajectories.

ED staff, patients and their caregivers consider the ED setting an uncomfortable situation for patients at risk of approaching death [13]. Besides the hectic and noisy environment of the ED, there is little space for family members to stay with their sick relatives and to conduct end-of-life discussions. Palliative patients often have a lower priority than patients with acute life-threatening illnesses and therefore spend a lot of time waiting at the ED [15]. The overwhelming environment of the ED and uncertainty about the situation increases psychological distress and anxiety in patients and their caregivers [21]. For ED physicians, an important reason that makes it difficult to provide optimal care to palliative patients is that they have no long-lasting relationships $[13,22]$. Moreover, they are not trained to provide adequate symptom management for and to discuss end-of-life decisions [13, 21, 22]. Notwithstanding, ED physicians are willing to provide palliative care and indicated that in order to enhance a 'good death', attention should be directed to the care needs and wishes of patients in the palliative phase visiting the ED [23, 24]. In our study, patients were exposed to many diagnostic tests (83\% underwent blood tests, $63 \%$ diagnostic imaging) and stayed at the ED for $3.5 \mathrm{~h}$ on average, which was followed by hospitalization in over $75 \%$. Since most patients prefer to spend the end of their life at home, these outcomes are undesirable [3].

Few patients in our study had limitations on life-sustaining treatments documented, suggesting that palliative care needs and approaching death had not yet been discussed. Patients and caregivers who are unprepared for or unaware of the problems and symptoms that may occur at the end of life are more likely to visit the ED at the end of life [15, 25], especially during out-of-office hours $[8,13,26]$. This is supported by our results: $34 \%$ of the patients referred themselves to the ED and $52 \%$ of the ED visits occurred out-of-office hours. Several 
Table 3 Characteristics of ED visit and follow-up

\begin{tabular}{|c|c|c|}
\hline Visit- and follow-up characteristics & $N$ & $(\%$ of 420$)$ \\
\hline Diagnostic imaging & 266 & $(63.3)$ \\
\hline Laboratory tests performed & 350 & $(83.3)$ \\
\hline \multicolumn{3}{|l|}{ Clinical diagnosis } \\
\hline Infection or fever & 86 & $(20.5)$ \\
\hline Bronchopulmonary insufficiency & 54 & $(12.9)$ \\
\hline Renal insufficiency or hydronephrosis & 47 & $(11.2)$ \\
\hline Cachexia & 40 & $(9.5)$ \\
\hline Ascites & 34 & $(8.1)$ \\
\hline Pleural effusion & 31 & $(7.4)$ \\
\hline Bleeding & 30 & $(7.1)$ \\
\hline Jaundice & 23 & $(5.5)$ \\
\hline Hypercalcemia & 20 & $(4.8)$ \\
\hline Ileus or passage disturbances & 18 & $(4.3)$ \\
\hline Neuropathy or plexopathy & 17 & $(4.0)$ \\
\hline Seizure & 13 & $(3.1)$ \\
\hline Urine retention & 13 & $(3.1)$ \\
\hline Fracture & 10 & $(2.4)$ \\
\hline Coma & 8 & $(1.9)$ \\
\hline Pulmonary embolism & 8 & $(1.9)$ \\
\hline Deep venous thrombosis & 7 & $(1.7)$ \\
\hline Delirium & 6 & $(1.4)$ \\
\hline Spinal cord compression & 5 & $(1.2)$ \\
\hline Any treatment initiated at ED & 230 & $(54.8)$ \\
\hline Time spent at ED, median (range) & 03:29 & $(00: 12-18: 01)$ \\
\hline \multicolumn{3}{|l|}{ Limitations on life-sustaining treatments $^{\mathrm{a}}$} \\
\hline Discussed, none documented & 10 & $(2.4)$ \\
\hline Discussed and documented & 297 & $(70.7)$ \\
\hline Not discussed & 113 & $(26.9)$ \\
\hline Hospitalization after ED visit & 319 & $(76.0)$ \\
\hline Survival after ED visit in days, median $(95 \% \mathrm{CI})$ & 18 & $(15-21)$ \\
\hline Death within 7 days after ED visit & 104 & $(24.8)$ \\
\hline Death within 14 days after ED visit & 170 & $(40.5)$ \\
\hline Death within 30 days after ED visit & 274 & $(65.2)$ \\
\hline Death within 60 days after ED visit & 370 & $(88.1)$ \\
\hline \multicolumn{3}{|l|}{ Place of death } \\
\hline Hospital $^{\mathrm{b}}$ & 124 & $(29.5)$ \\
\hline Home or residential home & 165 & $(39.3)$ \\
\hline Hospice & 46 & $(11.0)$ \\
\hline Nursing home & 4 & $(1.0)$ \\
\hline Unknown & 81 & $(19.3)$ \\
\hline
\end{tabular}

$E D$ emergency department, $h$ hours, mins minutes, $I Q$ range interquartile range, ICU intensive care unit

${ }^{\mathrm{a}}$ During visit/after discharge

${ }^{\mathrm{b}}$ One patient died at the ED (0.2\%), 113 at a hospital ward (26.9\%), and 10 at the ICU $(2.4 \%)$ studies reported that the majority of the ED visits are undesirable and avoidable, especially those by patients with a very short survival [5, 26, 27]. End-of-life discussions have shown to have the potential to prevent ED visits in the last month of life in patients with ovarian cancer [28] and stage IV lung and colorectal cancer [29]. Community-based palliative care effectively reduced the number of ED visits in the last phase of life in advanced cancer patients [30] and in the general patient population [31, 32]. Furthermore, meta-analysis of numerous randomized clinical trials proved that integration of palliative 
Table 4 Risk factors for death after ED visit

\begin{tabular}{|c|c|c|c|c|c|c|}
\hline \multirow[t]{2}{*}{ Predictors } & \multicolumn{3}{|c|}{ Univariable analysis } & \multicolumn{3}{|c|}{ Multivariable analysis } \\
\hline & HR & $95 \% \mathrm{CI}$ & $p$ value & HR & $95 \% \mathrm{CI}$ & $p$ value \\
\hline Primary lung tumour & 1.67 & $1.28-2.18$ & $<0.0001$ & 1.69 & $1.29-2.21$ & $<0.0001$ \\
\hline ED-admission for new and acute problem & 0.98 & $0.79-1.20$ & 0.81 & & & \\
\hline Limitations on LSTs before ED visit & 1.26 & $1.02-1.54$ & 0.029 & & & NS \\
\hline \multicolumn{7}{|l|}{ Main symptom at the ED } \\
\hline Neurologic deterioration & 1.85 & $1.29-2.66$ & 0.001 & 2.01 & $1.38-2.92$ & $<0.0001$ \\
\hline Dyspnoea & 1.48 & $1.17-1.88$ & 0.001 & 1.57 & $1.23-2.00$ & $<0.0001$ \\
\hline \multicolumn{7}{|l|}{ Clinical diagnosis } \\
\hline Bleeding & 1.37 & $0.95-1.99$ & 0.096 & & & NS \\
\hline Cachexia & 1.43 & $1.03-1.98$ & 0.034 & & & NS \\
\hline Hypercalcemia & 1.80 & $1.14-2.83$ & 0.011 & 1.92 & $1.21-3.03$ & 0.005 \\
\hline Jaundice & 2.21 & $1.44-3.39$ & $<0.0001$ & 2.11 & $1.37-3.26$ & 0.001 \\
\hline
\end{tabular}

$H R$ hazard ratio, $C I$ confidence interval, $L S T$ s life-sustaining treatments, $E D$ emergency department care early in the disease trajectory improves health-related quality of life and symptom intensity in patients with advanced cancer [33]. Advance care planning and out-patient symptom management may help patients and their caregivers to prepare for the end-of-life trajectory and to avoid unnecessary ED visits by supporting coping with deteriorating health $[21,34]$. Although palliative care is often perceived as end-oflife care, palliative care can be provided concurrently with standard care [35]. Hence, timely initiation of palliative care is possible and helps to avoid unnecessary ED visits and can improve quality of life in the end-of-life phase.

Although early palliative care can avoid part of the ED visits at the end of life, there will still be patients visiting the ED for symptoms that are distressing and unmanageable at home. Additionally, patients may visit the ED when community palliative care services are not available, e.g., outside office hours $[15,21]$. ED visits can be an opportunity to recognize high symptom burden and acute deterioration, which should trigger initiation of appropriate palliative care. This is also known as ED-initiated palliative care [36, 37]. Grudzen et al. conducted a randomized clinical trial in 2016 on palliative care consultations initiated at the ED in patients with advanced cancer and found that it significantly improved their quality of life [37]. Examples of ED-initiated palliative care are, among others, consultations by a specialized in-hospital team, community-based care by a homecare team or hospice team, telephone-based interventions, or admissions to a hospice or a palliative care unit [33]. Our finding that physicians documented more limitations on LSTs after the ED visit might indicate that they were well aware of changes in disease trajectories, creating an opportunity for effective ED-initiated palliative care. To facilitate cooperation with palliative care services, both at home and in the hospital, it is recommended to have a checklist with standardized criteria [38] for referral with contact details of the palliative care services easily available at the ED. An international consensus panel of 60 experts on palliative cancer care formulated 11 criteria for referral to specialized palliative care: nine needs-based criteria (severe physical symptoms, severe emotional symptoms, request for hastened death, spiritual or existential crisis, need for assistance with decision-making or care planning, referral on patient's request, delirium, brain or leptomeningeal metastases, spinal cord compression or cauda equine) and two timebased criteria (within 3 months of diagnosis of advanced cancer or incurable cancer for patients with a median survival of 1 year of less, diagnosis of advanced cancer with progressive disease despite second-line systemic therapy) [39]. The severity of symptoms can be measured by using the Edmonton Symptom Assessment Scale (ESAS), a patient-reported outcome measure for symptoms prevalent in the palliative phase which is manageable at the ED [40, 41]. Although the ESAS is not yet validated in the ED setting, a study by Barbera et al. shows that poor symptom burden scores were associated with higher usage of the ED, suggesting that patients visit the ED particularly with high palliative care needs which should be acted upon as soon as possible [42].

To identify patients in whom palliative care should be initiated, survival prediction tools such as the Surprise Question, and prediction scores such as the Palliative Prognostic Score (PaP), Palliative Prognostic Index (PPI), Glascow Prognostic Score (GPS) and Prognosis in Palliative Care Study (PiPS) are described [18, 43]. However, these tools are not validated in patients with advanced cancer visiting the ED. To facilitate appropriate and ED-initiated palliative care, we constructed a flowchart to help ED staff identify advanced cancer patients with urgent palliative care needs (Fig. 1). In this flowchart, factors from the current study associated with approaching death, suggesting urgent palliative care needs, are depicted: primary lung tumour, dyspnoea, neurologic deterioration, jaundice and hypercalcemia. Other known triggers for 
Risk assessment at the ED for palliative care needs in patients with cancer

Ask yourself the following questions

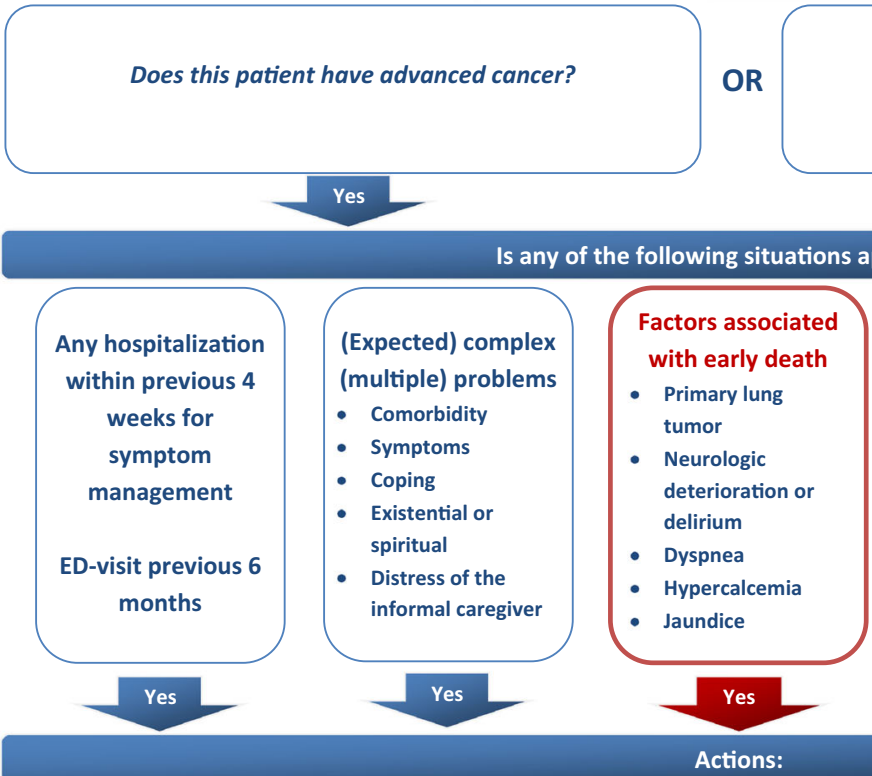

Would I be surprised if this patient died within the next year?

Downar 2017: The "surprise question" for predicting death in seriously ill patients No L

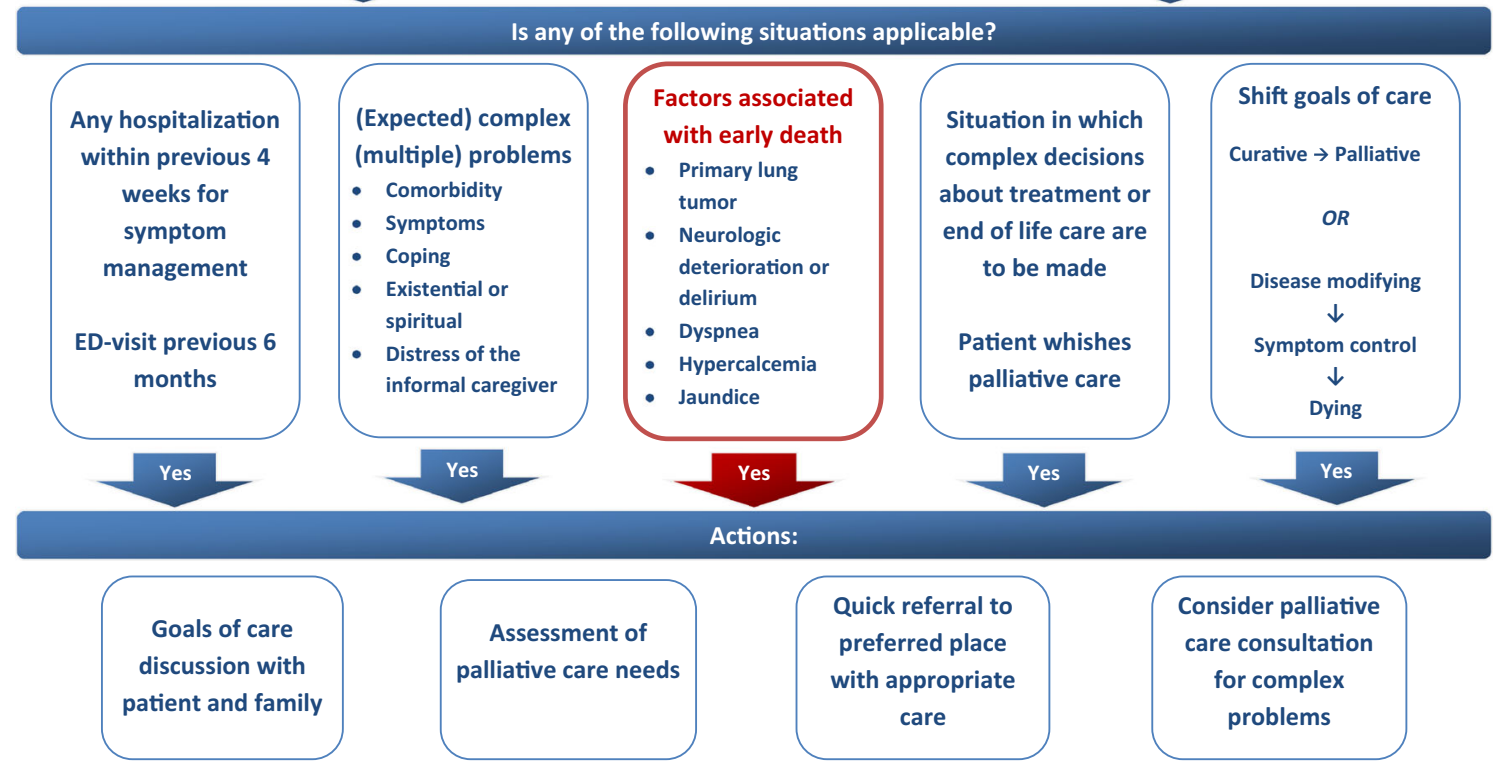

Fig. 1 Risk assessment at the ED for palliative care needs in patients with cancer

palliative care needs that are easily assessable at the ED were added to the flowchart. In other studies in advanced cancer patients, dyspnoea and respiratory distress are reported as risk factors for approaching death, as are neurological deterioration and gastro-intestinal problems $[9,44,45]$. Hypercalcemia is probably predictive of death because it can be a marker for progressive disease in patients with bone metastases or paraneoplastic syndromes [46]. Cachexia was associated with approaching death in our univariable model, and delirium was included in the group with neurological deterioration. Although a decline in performance status is a strong predictor for death [47, 48], we could not find an association with death, probably because values were missing for many patients. If advanced cancer patients with urgent palliative care needs are identified at the ED, ED staff may choose to consult the hospital palliative care consultation team. Also, tools for unmet palliative needs screening are available, such as the 'Screen for Palliative and End-of-life care needs in the Emergency Department (SPEED)' tool [49] or the shorter 5-SPEED tool [50]. The SPEED is the only palliative care needs assessment tool that is validated for use at the ED; however, it is not yet validated in patients with advanced cancer.

This pragmatic study gives insight into the end-of-life trajectory of patients with advanced cancer who visit the ED. We are aware that the retrospective design of our study could have led to registration bias and unmeasured confounding. Selection bias was introduced by the choice to limit inclusion to cancer patients in the palliative phase of their disease who died within 3 months after the ED visit. We aimed to describe the population of advanced cancer patients who visited the ED at the end of their life, because especially in those patients, appropriate care should be initiated at the ED. Lastly, because the end-of-life trajectory, especially in the last 3 months, has not been subject to major changes, we consider our data collected from 2011 to 2014 still relevant to the present situation. Further research should be conducted to validate survival prediction tools and needs assessment tools for patients with advanced cancer visiting the $\mathrm{ED}$ and to evaluate implementation of models of ED-initiated palliative care.

\section{Conclusion}

Advanced cancer patients received limited palliative care before visiting the ED in the last 3 months of their life. The ED visit often marked physical deterioration and triggered revision of limitations on life-sustaining treatments. Many patients were hospitalized and a substantial percentage died within 1 week and in-hospital. Timely recognition of patients at high risk of approaching death and awareness of the potential of ED-initiated palliative care among ED-staff can improve the end-of-life trajectory of these patients. 
Acknowledgements We would like to thank our students (Leanne Smit, Tobias Wieles, Mathijs Kruizinga and Iris Groeneveld), and Lotte van der Stap and our colleagues at the Center of Expertise Palliative Care of the Leiden University Medical Center.

Author contributions Mary-Joanne Verhoef, Nanda Horeweg, Ellen de Nijs and Yvette van der Linden provided the conceptual framework for this study, analysed the data and wrote the manuscript. Marta Fiocco contributed to data-analysis. Corrie Marijnen, Anouk Jochems, Jaap Fogteloo and Christian Heringhaus contributed to data-collection and provided critical comments on the manuscript.

Funding This research did not receive any specific grant from funding agencies in the public, commercial or not-for-profit sectors.

\section{Compliance with ethical standards}

Conflict of interest The authors declare that they have no conflict of interest.

Informed consent As approved by the Medical Ethics Committee of the LUMC and according to Dutch and European law, informed consent from patients was not necessary because of the retrospective design of this study.

Open Access This article is distributed under the terms of the Creative Commons Attribution 4.0 International License (http:// creativecommons.org/licenses/by/4.0/), which permits unrestricted use, distribution, and reproduction in any medium, provided you give appropriate credit to the original author(s) and the source, provide a link to the Creative Commons license, and indicate if changes were made.

\section{References}

1. Global Burden of Disease Cancer C, Fitzmaurice C, Akinyemiju TF, Al Lami FH, Alam T, Alizadeh-Navaei R, Allen C, Alsharif U, Alvis-Guzman N, Amini E, Anderson BO, Aremu O, Artaman A, Asgedom SW, Assadi R, Atey TM, Avila-Burgos L, Awasthi A, Ba Saleem HO, Barac A, Bennett JR, Bensenor IM, Bhakta N, Brenner H, Cahuana-Hurtado L, Castaneda-Orjuela CA, Catala-Lopez F, Choi JJ, Christopher DJ, Chung SC, Curado MP, Dandona L, Dandona R, das Neves J, Dey S, Dharmaratne SD, Doku DT, Driscoll TR, Dubey M, Ebrahimi H, Edessa D, El-Khatib Z, Endries AY, Fischer F, Force LM, Foreman KJ, Gebrehiwot SW, Gopalani SV, Grosso G, Gupta R, Gyawali B, Hamadeh RR, Hamidi S, Harvey J, Hassen HY, Hay RJ, Hay SI, Heibati B, Hiluf MK, Horita N, Hosgood HD, Ilesanmi OS, Innos K, Islami F, Jakovljevic MB, Johnson SC, Jonas JB, Kasaeian A, Kassa TD, Khader YS, Khan EA, Khan G, Khang YH, Khosravi MH, Khubchandani J, Kopec JA, Kumar GA, Kutz M, Lad DP, Lafranconi A, Lan Q, Legesse Y, Leigh J, Linn S, Lunevicius R, Majeed A, Malekzadeh R, Malta DC, Mantovani LG, McMahon BJ, Meier T, Melaku YA, Melku M, Memiah P, Mendoza W, Meretoja TJ, Mezgebe HB, Miller TR, Mohammed S, Mokdad AH, Moosazadeh M, Moraga P, Mousavi SM, Nangia V, Nguyen CT, Nong VM, Ogbo FA, Olagunju AT, Pa M, Park EK, Patel T, Pereira DM, Pishgar F, Postma MJ, Pourmalek F, Qorbani M, Rafay A, Rawaf S, Rawaf DL, Roshandel G, Safiri S, Salimzadeh H, Sanabria JR, Santric Milicevic MM, Sartorius B, Satpathy M, Sepanlou SG, Shackelford KA, Shaikh MA, Sharif-Alhoseini M, She J, Shin MJ, Shiue I, Shrime MG, Sinke AH, Sisay M, Sligar A,
Sufiyan MB, Sykes BL, Tabares-Seisdedos R, Tessema GA, ToporMadry R, Tran TT, Tran BX, Ukwaja KN, Vlassov VV, Vollset SE, Weiderpass E, Williams HC, Yimer NB, Yonemoto N, Younis MZ, Murray CJL, Naghavi M (2018) Global, regional, and National Cancer Incidence, mortality, years of life lost, years lived with disability, and disability-adjusted life-years for 29 Cancer groups, 1990 to 2016: a systematic analysis for the global burden of disease study. JAMA Oncol 4:1553-1568. https://doi.org/10.1001/ jamaoncol.2018.2706

2. World Health Organization (2018) WHO Definition of Palliative Care. http://www.who.int/cancer/palliative/definition/en/. Accessed 5 Oct 2018

3. Gomes B, Higginson IJ, Calanzani N, Cohen J, Deliens L, Daveson BA, Bechinger-English D, Bausewein C, Ferreira PL, Toscani F, Menaca A, Gysels M, Ceulemans L, Simon ST, Pasman HR, Albers G, Hall S, Murtagh FE, Haugen DF, Downing J, Koffman J, Pettenati F, Finetti S, Antunes B, Harding R, Prisma (2012) Preferences for place of death if faced with advanced cancer: a population survey in England, Flanders, Germany, Italy, the Netherlands, Portugal and Spain. Ann Oncol 23(8):2006-2015. $\mathrm{https} / / /$ doi.org/10.1093/annonc/mdr602

4. Higginson IJ, Sen-Gupta GJ (2000) Place of care in advanced cancer: a qualitative systematic literature review of patient preferences. J Palliat Med 3(3):287-300. https://doi.org/10.1089/jpm.2000.3. 287

5. Barbera L, Taylor C, Dudgeon D (2010) Why do patients with cancer visit the emergency department near the end of life? CMAJ 182(6):563-568. https://doi.org/10.1503/cmaj.091187

6. Earle CC, Neville BA, Landrum MB, Ayanian JZ, Block SD, Weeks JC (2004) Trends in the aggressiveness of cancer care near the end of life. J Clin Oncol 22(2):315-321. https://doi.org/10. 1200/JCO.2004.08.136

7. Qureshi D, Tanuseputro P, Perez R, Seow H (2018) Place of Care trajectories in the last two Weeks of life: a population-based cohort study of Ontario decedents. J Palliat Med 21:1588-1595. https:// doi.org/10.1089/jpm.2018.0049

8. Mayer DK, Travers D, Wyss A, Leak A, Waller A (2011) Why do patients with cancer visit emergency departments? Results of a 2008 population study in North Carolina. J Clin Oncol 29(19): 2683-2688. https://doi.org/10.1200/JCO.2010.34.2816

9. Geraci JM, Tsang W, Valdres RV, Escalante CP (2006) Progressive disease in patients with cancer presenting to an emergency room with acute symptoms predicts short-term mortality. Support Care Cancer 14(10):1038-1045. https://doi.org/10.1007/s00520-0060053-6

10. Mercadante S, Porzio G, Valle A, Aielli F, Costanzo V, Adile C, Spedale V, Casuccio A, Home Care Italy G (2012) Emergencies in patients with advanced cancer followed at home. J Pain Symptom Manag 44(2):295-300. https://doi.org/10.1016/j.jpainsymman. 2011.07.016

11. Mercadante S, Masedu F, Valenti M, Mercadante A, Aielli F (2016) The characteristics of advanced cancer patients followed at home, but admitted to the hospital for the last days of life. Intern Emerg Med 11(5):713-718. https://doi.org/10.1007/s11739-016-1402-1

12. Henson LA, Higginson IJ, Daveson BA, Ellis-Smith C, Koffman J, Morgan M, Gao W, BuildCare (2016) I'll be in a safe place': a qualitative study of the decisions taken by people with advanced cancer to seek emergency department care. BMJ Open 6(11): e012134. https://doi.org/10.1136/bmjopen-2016-012134

13. Cooper E, Hutchinson A, Sheikh Z, Taylor P, Townend W, Johnson MJ (2018) Palliative care in the emergency department: a systematic literature qualitative review and thematic synthesis. Palliat Med 32:1443-1454. https://doi.org/10.1177/0269216318783920

14. Jelinek GA, Marck CH, Weiland TJ, Philip J, Boughey M, Weil J, Lane $\mathrm{H}$ (2013) Caught in the middle: tensions around the emergency department care of people with advanced cancer. Emerg Med 
Australas 25(2):154-160. https://doi.org/10.1111/1742-6723. 12047

15. Smith AK, Fisher J, Schonberg MA, Pallin DJ, Block SD, Forrow L, Phillips RS, McCarthy EP (2009) Am I doing the right thing? Provider perspectives on improving palliative care in the emergency department. Ann Emerg Med 54(1):86-93, 93 e81. https://doi. org/10.1016/j.annemergmed.2008.08.022

16. Marck CH, Weil J, Lane H, Weiland TJ, Philip J, Boughey M, Jelinek GA (2014) Care of the dying cancer patient in the emergency department: findings from a national survey of Australian emergency department clinicians. Intern Med J 44(4):362-368. https:// doi.org/10.1111/imj.12379

17. Lane H, Weil J, Jelinek GA, Boughey M, Marck CH, Weiland TJ, Haydon A, Philip J (2014) Ideal care and the realities of practice: interdisciplinary relationships in the management of advanced cancer patients in Australian emergency departments. Support Care Cancer 22(4):1029-1035. https://doi.org/10.1007/s00520-0132054-6

18. Hui D (2015) Prognostication of survival in patients with advanced Cancer: predicting the unpredictable? Cancer Control 22(4):489497. https://doi.org/10.1177/107327481502200415

19. Lynn Joanne ADM (2003) Living Well at the End of Life. Adapting Health Care to Serious Chronic Illness in Old Age. RAND Health, Santa Monica

20. Oken MM, Creech RH, Tormey DC, Horton J, Davis TE, McFadden ET, Carbone PP (1982) Toxicity and response criteria of the eastern cooperative oncology group. Am J Clin Oncol 5(6): 649-655

21. Smith AK, Schonberg MA, Fisher J, Pallin DJ, Block SD, Forrow L, McCarthy EP (2010) Emergency department experiences of acutely symptomatic patients with terminal illness and their family caregivers. J Pain Symptom Manag 39(6):972-981. https://doi.org/ 10.1016/j.jpainsymman.2009.10.004

22. Stone SC, Mohanty S, Grudzen CR, Shoenberger J, Asch S, Kubricek K, Lorenz KA (2011) Emergency medicine physicians' perspectives of providing palliative care in an emergency department. J Palliat Med 14(12):1333-1338. https://doi.org/10.1089/ jpm.2011.0106

23. Decker K, Lee S, Morphet J (2015) The experiences of emergency nurses in providing end-of-life care to patients in the emergency department. Australas Emerg Nurs J 18(2):68-74. https://doi.org/ 10.1016/j.aenj.2014.11.001

24. Shearer FM, Rogers IR, Monterosso L, Ross-Adjie G, Rogers JR (2014) Understanding emergency department staff needs and perceptions in the provision of palliative care. Emerg Med Australas 26(3):249-255. https://doi.org/10.1111/1742-6723.12215

25. Korte-Verhoef R (2014) Reasons and Avoidability of Hospitalisations at the End of Life. Perspectives of GPs, Nurses and Family Carers. VU University Medical Center, Ede

26. Wallace EM, Cooney MC, Walsh J, Conroy M, Twomey F (2013) Why do palliative care patients present to the emergency department? Avoidable or unavoidable? Am J Hosp Palliat Care 30(3): 253-256. https://doi.org/10.1177/1049909112447285

27. Delgado-Guay MO, Kim YJ, Shin SH, Chisholm G, Williams J, Allo J, Bruera E (2015) Avoidable and unavoidable visits to the emergency department among patients with advanced cancer receiving outpatient palliative care. J Pain Symptom Manag 49(3): 497-504. https://doi.org/10.1016/j.jpainsymman.2014.07.007

28. Lopez-Acevedo M, Havrilesky LJ, Broadwater G, Kamal AH, Abernethy AP, Berchuck A, Alvarez Secord A, Tulsky JA, Valea F, Lee PS (2013) Timing of end-of-life care discussion with performance on end-of-life quality indicators in ovarian cancer. Gynecol Oncol 130(1):156-161. https://doi.org/10.1016/j.ygyno.2013.04. 010

29. Mack JW, Cronin A, Keating NL, Taback N, Huskamp HA, Malin JL, Earle CC, Weeks JC (2012) Associations between end-of-life discussion characteristics and care received near death: a prospective cohort study. J Clin Oncol 30(35):4387-4395. https://doi.org/ 10.1200/JCO.2012.43.6055

30. Henson LA, Gao W, Higginson IJ, Smith M, Davies JM, EllisSmith C, Daveson BA (2015) Emergency department attendance by patients with cancer in their last month of life: a systematic review and meta-analysis. J Clin Oncol 33(4):370-376. https:// doi.org/10.1200/JCO.2014.57.3568

31. Spilsbury K, Rosenwax L, Arendts G, Semmens JB (2017) The Association of Community-Based Palliative Care with Reduced Emergency Department Visits in the last year of life varies by patient factors. Ann Emerg Med 69(4):416-425. https://doi.org/10. 1016/j.annemergmed.2016.11.036

32. Spilsbury K, Rosenwax L, Arendts G, Semmens JB (2017) The impact of community-based palliative care on acute hospital use in the last year of life is modified by time to death, age and underlying cause of death. A population-based retrospective cohort study. PLoS One 12(9):e0185275. https://doi.org/10.1371/journal.pone. 0185275

33. Haun MW, Estel S, Rucker G, Friederich HC, Villalobos M, Thomas M, Hartmann M (2017) Early palliative care for adults with advanced cancer. Cochrane Database Syst Rev (6):CD011129. https://doi.org/10.1002/14651858.CD011129.pub2

34. Wright CM, Youens D, Moorin RE (2018) Earlier initiation of community-based palliative Care is associated with fewer unplanned hospitalizations and emergency department presentations in the final months of life: a population-based study among Cancer decedents. J Pain Symptom Manag 55(3):745-754 e748. https:// doi.org/10.1016/j.jpainsymman.2017.11.021

35. Vanbutsele G, Pardon K, Van Belle S, Surmont V, De Laat M, Colman R, Eecloo K, Cocquyt V, Geboes K, Deliens L (2018) Effect of early and systematic integration of palliative care in patients with advanced cancer: a randomised controlled trial. Lancet Oncol 19(3):394-404. https://doi.org/10.1016/S1470-2045(18) 30060-3

36. Kistler EA, Sean Morrison R, Richardson LD, Ortiz JM, Grudzen CR (2015) Emergency department-triggered palliative care in advanced cancer: proof of concept. Acad Emerg Med 22(2):237-239. https://doi.org/10.1111/acem.12573

37. Grudzen CR, Richardson LD, Johnson PN, Hu M, Wang B, Ortiz JM, Kistler EA, Chen A, Morrison RS (2016) Emergency department-initiated palliative Care in Advanced Cancer: a randomized clinical trial. JAMA Oncol 2:591-598. https://doi.org/10.1001/ jamaoncol.2015.5252

38. Hui D, Hannon BL, Zimmermann C, Bruera E (2018) Improving patient and caregiver outcomes in oncology: team-based, timely, and targeted palliative care. CA Cancer J Clin 68(5):356-376. https://doi.org/10.3322/caac. 21490

39. Hui D, Mori M, Watanabe SM, Caraceni A, Strasser F, Saarto T, Cherny N, Glare P, Kaasa S, Bruera E (2016) Referral criteria for outpatient specialty palliative cancer care: an international consensus. Lancet Oncol 17(12):e552-e559. https://doi.org/10.1016/ S1470-2045(16)30577-0

40. Hui D, Bruera E (2017) The Edmonton symptom assessment system 25 years later: past, present, and future developments. J Pain Symptom Manag 53(3):630-643. https://doi.org/10.1016/j. jpainsymman.2016.10.370

41. Hoerger M, Greer JA, Jackson VA, Park ER, Pirl WF, El-Jawahri A, Gallagher ER, Hagan T, Jacobsen J, Perry LM, Temel JS (2018) Defining the elements of early palliative Care that are associated with patient-reported outcomes and the delivery of end-of-life Care. J Clin Oncol 36(11):1096-1102. https://doi.org/10.1200/JCO.2017. 75.6676

42. Barbera L, Atzema C, Sutradhar R, Seow H, Howell D, Husain A, Sussman J, Earle C, Liu Y, Dudgeon D (2013) Do patient-reported symptoms predict emergency department visits in cancer patients? 
A population-based analysis. Ann Emerg Med 61(4):427-437 e425. https://doi.org/10.1016/j.annemergmed.2012.10.010

43. Downar J, Goldman R, Pinto R, Englesakis M, Adhikari NK (2017) The "surprise question" for predicting death in seriously ill patients: a systematic review and meta-analysis. CMAJ 189(13):E484E493. https://doi.org/10.1503/cmaj.160775

44. Maltoni M, Caraceni A, Brunelli C, Broeckaert B, Christakis N, Eychmueller S, Glare P, Nabal M, Vigano A, Larkin P, De Conno F, Hanks G, Kaasa S, Steering Committee of the European Association for Palliative C (2005) Prognostic factors in advanced cancer patients: evidence-based clinical recommendations-a study by the steering Committee of the European Association for palliative Care. J Clin Oncol 23(25):6240-6248. https://doi.org/10.1200/ JCO.2005.06.866

45. Trajkovic-Vidakovic M, de Graeff A, Voest EE, Teunissen SC (2012) Symptoms tell it all: a systematic review of the value of symptom assessment to predict survival in advanced cancer patients. Crit Rev Oncol Hematol 84(1):130-148. https://doi.org/10. 1016/j.critrevonc.2012.02.011

46. de Graeff A KR (2009) Richtlijn Hypercalciemie. https://www. oncoline.n1/hypercalciemie. Accessed 16-08-2018

47. Seow H, Barbera L, Sutradhar R, Howell D, Dudgeon D, Atzema C, Liu Y, Husain A, Sussman J, Earle C (2011) Trajectory of performance status and symptom scores for patients with cancer during the last six months of life. J Clin Oncol 29(9):1151-1158. https://doi.org/10.1200/JCO.2010.30.7173

48. Evans C, McCarthy M (1985) Prognostic uncertainty in terminal care: can the Karnofsky index help? Lancet 1(8439):1204-1206

49. George N, Barrett N, McPeake L, Goett R, Anderson K, Baird J (2015) Content validation of a novel screening tool to identify emergency department patients with significant palliative Care needs. Acad Emerg Med 22(7):823-837. https://doi.org/10.1111/ acem. 12710

50. Reuter Q, Marshall A, Zaidi H, Sista P, Powell ES, McCarthy DM, Dresden SM (2019) Emergency department-based palliative interventions: a novel approach to palliative Care in the Emergency Department. J Palliat Med. https://doi.org/10.1089/jpm.2018.0341

Publisher's note Springer Nature remains neutral with regard to jurisdictional claims in published maps and institutional affiliations. 